\title{
Picture This! Reflecting on the Use of Posters as Expressions of PhD Research Projects
}

Kate E. Rowlands, Christopher J. Rees, Hana Alsultan, Daniel A. Diaz, Francisca Alvarez Figueroa, Yuttachai Inpa, Johanna Aguilera Munoz, Kunkanit Sutamchai, and $X i X i$

\section{University of Manchester, United Kingdom}

\begin{abstract}
The presentation of posters at scientific conferences to visually represent research projects is a widespread international practice. The main purpose of this paper is to offer reflections relating to posters as visual representations of research studies conducted by $\mathrm{PhD}$ candidates. As the basis for our reflections, we consider the main purposes and intended learning outcomes linked to posters and reflect on some of the design and assessment issues associated with the multi-faceted purposes of posters in contexts such as postgraduate research conferences. Notably, the paper includes a set of illustrative vignettes written by a group of $\mathrm{PhD}$ students from the Faculty of Humanities at the University of Manchester who were required to design and exhibit posters at an annually held postgraduate research conference. This reflexive dialogue raises a series of issues for consideration by those who are actively involved with the design, presentation, observation and assessment of posters produced by $\mathrm{PhD}$ candidates.
\end{abstract}

Keywords: Conferences, Posters, PhD, Criteria, Development, Judgement, Assessment 


\section{Introduction}

"The poster proper is a printed sheet produced for the purpose of advertisement. It may be almost wholly pictorial or consist of lettering only". So wrote W.S. Rogers in 1914 in a treatise endearingly entitled: "The modern poster; its essentials and significance" Rogers (1914: 186). Since the release of this publication over 100 years ago, posters have become a ubiquitous feature of academic life across a wide variety of academic disciplines (Carr, Loucks, and Blöschl 2018; Fakunle, Dollinger, AllaMensah and Izard, 2019; Kuzhabekova and Temerbayeva, 2018). The main aim of this paper is to offer reflections relating to the use of posters as visual representations of research studies conducted by $\mathrm{PhD}$ candidates. In focusing on issues such as the challenges involved with designing posters to represent abridged and simplified pictures of complex research projects, the guidance provided to $\mathrm{PhD}$ students, and the assessment of posters in teaching and learning settings, we aim to raise awareness of the extent to which the poster has emerged as a method of visually representing postgraduate research projects.

The paper is structured is follows. First, we consider the main purposes and intended learning outcomes linked to the use of posters on $\mathrm{PhD}$ programmes. We then seek to clarify the advice provided to $\mathrm{PhD}$ students when designing posters which are intended to encapsulate the essence of their research projects. Finally, we reflect on some design and assessment issues associated with the multi-faceted purposes of posters in contexts such as postgraduate research conferences. Notably, the paper includes a set of illustrative vignettes written by a group of $\mathrm{PhD}$ students from the Faculty of Humanities at the University of Manchester; all of these postgraduate researchers were required, due to a specific component of their PhD programme, to design and exhibit posters at an annually held postgraduate research conference.

\section{What is the purpose of a poster designed to represent a PhD study?}

It has been argued by various writers that poster presentations are an effective teaching mechanism for helping students to develop their arguments and voices in academic settings (Lynch, 2018). This viewpoint is particularly pertinent to $\mathrm{PhD}$ candidates who are seeking to acquire the skills necessary to conduct independent research. Thus, in their guide for prospective and current doctoral candidates, the UK's Quality Assurance Agency (QAA) draws attention to a set of activities and experiences in which doctoral candidates can engage to "support the personal and professional development of researchers as well as being a formal means of developing as institutional researchers" (QAA, 2011: 12). Specifically, under the heading of dissemination of research knowledge, the QAA states that this development takes places when doctoral candidates engage with conference and seminar posters. Thus, from the outset of this reflection, we highlight two overriding purposes of posters when designed and exhibited by $\mathrm{PhD}$ students. The first is to disseminate knowledge and the second is to enhance the personal and professional development of $\mathrm{PhD}$ candidates. Clearly, these two purposes should not be treated discretely as the effectiveness with which research findings are disseminated is, in part, dependent upon the research-related skills and capabilities of the researcher in question.

International Journal of Management and Applied Research, 2020, Vol. 7, No. 3 
This initial foray into the field of posters as visual representations of $\mathrm{PhD}$ projects offers an early indication of the inextricable links that exist between the essence of the $\mathrm{PhD}$ candidate's research project, the design and content of the poster, and the characteristics of the candidate. In effect, posters portray key features of all these elements. For example, the poster presents details about the purpose and design of the project; the poster displays evidence of the techniques and methods used by the candidate to express the essence of their project to an external audience; and the poster reveals underlying content and design choices made by the candidate in terms of what to include and exclude when constructing the poster (Persky, 2016). Notably, these features of posters attract different degrees of emphasis at different times.

At a general level, there is a plethora of advice available on how to design effective posters. For example, in an excellent practical contribution on poster design and presentation, Berg and Hicks (2017) cover a diverse range of topics such as types of posters, content and layout, visual appeal, and the use of space and imagery. Understandably, however, writers have found it more difficult to provide targeted and esoteric advice to PhD students about how to express the essence of a research project using a poster. Even within disciplinary boundaries, there are huge variations in approaches to $\mathrm{PhD}$ research projects which make it extremely to offer anything more that general advice about what content should be included in a poster presentation (Anderson et al., 2011; Rees and Rowlands, 2020). Having reflected about this issue, we subsequently struggled to identity guidelines which moved beyond general considerations (such as 'clearly state the purpose of the research', and 'provide information about the context in which the research is being conducted') leading us to recognise the extent to which poster design has to involve individualised and highly subjective decision-making due to the originality of $\mathrm{PhD}$ research projects.

\section{Poster presentations in practice}

As discussed above, various advantages have been claimed about the design process and act of presenting posters at academic and professional conferences. For example, it has been suggested that a poster presentation represents an opportunity to develop effective communication skills, partly because the activity encourages $\mathrm{PhD}$ candidates to become confident and clear about the purpose of their research (Flaherty et. al, 2018). Similarly, it has been argued that poster activities encourage the promotion of collaborative learning, as $\mathrm{PhD}$ candidates are provided with an opportunity to view and engage with their peers and reflect on their progress and visual representations (Mills et al., 2000). However, a concept which is often overlooked is how the candidate adapts lengthy sections of their written $\mathrm{PhD}$ work into a one sided poster or indeed whether this work can be summarised adequately into this format (Tanner and Chapman, 2012). Notably, one related problem with the presentation of posters as written work has been described as follows: "The most common mistake of posters is overcommunication; posters are intended to convey the main message, not be a manuscript (Persky, 2016: 162).

As we reflected upon this issue, we were forced to recognise some of our own underlying assumptions, namely, that we have assumed, rightly or wrongly, that it is

International Journal of Management and Applied Research, 2020, Vol. 7, No. 3 
actually possible to accomplish this task of condensing complex work in a meaningful way and, further, assumed that it is reasonable to require first year $\mathrm{PhD}$ candidates to this perform this task. Further, given the emphasis on the academic approach to a $\mathrm{PhD}$, it is also valuable to consider the absence of opportunities to 'practise' for the student, (Brown, 2001). In the majority of approaches to academic assessment, students are often given an opportunity to draft their work and receive feedback; yet during this process of designing and presenting a poster, that opportunity is limited and may account for some of the negative perception of poster presentations (Briggs, 2009; Lynch et al, 2012).

Another criticism of the visual representation of the $\mathrm{PhD}$ first year work is the lack of formal criteria against which projects should be assessed. In overall terms, the aim of poster presentations is to provide the audience with an expression of the essence of research projects using attractive and concise visual representations based on mixtures of text, tables, pictures and other presentation formats (Craddock and Matthias, 2009; Kinikin and Hench, 2012). Yet, in the absence of commonly adopted specific guidelines relating to the aesthetics of poster design, wide variations in academic content and visual presentation are usually evident (Brownlie, 2007). That is, the rudimentary familiarity of $\mathrm{PhD}$ candidates' knowledge of the diverse subjective criteria against which posters are judged by audience members is, to the least, problematic. Thus, while posters are likely to be judged in general terms against criteria such as the content, the visual presentation, oral communication, argumentation and oral defense of the poster (Moon, 2014), the assessment criteria used by specific members of the audience is usually shrouded in mystery and represents another uncertain aspect of the presentation of a poster by a $\mathrm{PhD}$ candidate.

In the sections of the paper below, we reflect further on these types of issues by considering a specific poster presentation event.

\section{Reviewing a $\mathrm{PhD}$ poster presentation event}

\subsection{Setting the scene}

Several PhD programmes in the Faculty of Humanities at the University of Manchester currently require first year $\mathrm{PhD}$ candidates to present posters which visually represent their research projects. These posters are presented at the end of the first year of the $\mathrm{PhD}$ programmes. The criteria for developing the posters are briefly outlined in the invitation emails and advise the $\mathrm{PhD}$ candidates about the size and orientation of the posters, as well as how to book a session with the graphics centre. There is no formal direction given outlining the evaluation or assessment criteria. Also present at the conference are $\mathrm{PhD}$ students in their second, third and sometimes fourth year along with supervisors and other members of academic staff.

On the day itself, the conference delegates are encouraged to walk around the poster section and talk to the students who can then further explain their work. In keeping with similar events, the focus of the presentation format is to showcase the $\mathrm{PhD}$ candidates' scholarly work and to encourage interaction with and between them. At this time, the delegates are also asked to judge which poster they perceive to be the

International Journal of Management and Applied Research, 2020, Vol. 7, No. 3 
best' by adding a tick by the relevant author's name on a paper ticket and submitting this to one of the conference organisers. In the following section, we consider this poster event in the light of conceptual issues raised earlier in the paper and also a set of vignettes written by some of the $\mathrm{PhD}$ candidates who presented posters.

\subsection{Reflecting on the event}

There are a number of key points which surfaced when, as a group of academics and $\mathrm{PhD}$ candidates, we reflected on the processes underpinning this conference event. At a fundamental level, the reflections led us to consider various reasons why poster presentations, involving the research projects of $\mathrm{PhD}$ students, have emerged as a common feature of international conferences. Returning to the opening lines of this paper, we reflected upon the perspective that the posters, which collectively are presented in a way akin to an exhibition of art, represent visually appealing advertisements for research projects. Similarly, we considered the extent to which conference organisers intend posters to serve developmental purposes as described by the QAA above. This multi-purpose approach to posters is illustrated well in Vignette One in which the $\mathrm{PhD}$ candidate draws attention to the potential for posters to share (or advertise) the main aspects of the research project while, at the same time, presenting a developmental opportunity which has the potential to enhance both the researcher and the study itself.

Vignette One I saw my poster presentation at the conference as an opportunity for sharing the main aspects of my PhD research while at the same time receiving comments from people who are familiar with the same or maybe a completely different research area (or specialisation). This poster opportunity provides the chance to enhance my perspective as a researcher and thus, the study itself.

(PhD candidate 1 - an international student from South America)

Vignette Two is helpful in highlighting that the perceived purpose of the poster is likely to be highly influential in its design. Thus, in Vignette Two the $\mathrm{PhD}$ candidate refers to the fact that they deliberately sought ways of designing the poster in a non-specialised and non-complex way in order to encourage feedback from "everyone", that is, regardless of their disciplinary background. What emerged from our reflections was that the presenters of posters may have very different views about the purposes of their posters; further, other delegates who examine and assess these posters hold their own ideas about why posters are being presented.

Vignette Two Presenting a poster was a way for me to get feedback from experts to develop my research. Presenting the poster in the first year of the study helped me to develop the research orientation through the ideas of the experts attending the conference. For me, the most difficult part was finding a shorthand method of presenting my ideas to take away complexity and open the way for feedback at the conference and on the internet from everyone.

(PhD candidate 2 - an international student from Asia)

Our reflections also highlighted the lack of information that was available to delegates about the perceptions of PhD candidates who had constructed and displayed posters at this event. Interestingly, while the event contained an exercise in which delegates were asked to rate posters on the basis of non-specified criteria, the $\mathrm{PhD}$ candidates

International Journal of Management and Applied Research, 2020, Vol. 7, No. 3 
themselves were not formally asked to evaluate the poster activity in relation to either their own research projects or their development as researchers.

Vignette Three Making the poster helped me to focus on what I want my research
to communicate within the given space (A2 or Al size). It helped me to make the
message of the research interesting and convenient. Interacting with audiences
helped me to gain feedback and see some aspects of the research that I might
have missed. It helped me make my research better. The poster session also
helped me to see other's works, both the good and bad parts so I could then
improve (or avoid putting something into) my research.

( $\mathrm{PhD}$ candidate 3 - an international student from Asia)

At an anecdotal level, it is evident from the vignettes that the poster activity was valued by some if not all of the doctoral students. For example, in keeping with the literature discussed above, the benefits of poster presentations are illustrated in Vignette Three in which the $\mathrm{PhD}$ candidate alludes to acquiring research dissemination skills, as well as to the value they placed on the vicarious learning opportunities which arose from engaging with the posters presented by other PhD candidates. Similarly, Vignette Four provides an insight into how the activity of representing the research project in the form of a poster helps some $\mathrm{PhD}$ candidates to step back from their own research when later writing the findings chapters for their theses.

Vignette Four The synthesis exercise of presenting my research in a very limited format for the poster helped me to visualize the backbone of my research. Asking myself what is central and what is peripheral was an exercise that I repeated later when facing the findings or when writing the results. In a work as extensive as a doctoral thesis, it was easy for me to get lost in the details (my supervisor can testify to that). So time and again I have returned to the exercise of taking distance and trying to delimit and construct an argument that is robust in academic terms.

(PhD candidate 4 - an international student from South America)

Another of the key issues we identified, and which resonates with themes in the literature review, stemmed from the $\mathrm{PhD}$ candidates' lack of prior experience of poster presentations. This perception is expressed in Vignette Five in which the $\mathrm{PhD}$ candidate refers to their lack of knowledge about putting a poster together and the time taken to figure out how to 'put things together nicely'. Interestingly, we see from Vignette Five, a perception that the emphasis in this event was placed on the design of posters when preparing $\mathrm{PhD}$ candidates for conferences. As indicated above, wider literature and web-based guidance suggest that the experience of this $\mathrm{PhD}$ candidate is not unusual. Thus, we highlight that some of the anxiety of presenting a poster may come not only from the poster development itself but also from the lack of opportunity for feedback and tight submission deadlines. Students often rely on informal feedback from their supervisor to fine tune drafts of work.

Vignette Five After one year of numerous readings, writing a literature review, and planning for research methods, working on my poster was a good way to distil and synthesise a lot of information about my research. Personally, I found it was quite relaxing and enjoyable to do something different by switching from merely writing to working on artwork and design. Since I had no experience in poster design, it took me a while to finally figure out how to put things together

International Journal of Management and Applied Research, 2020, Vol. 7, No. 3 
nicely, the layouts, colour schemes, and the appropriate photos. I was not given enough information about the content criteria. There was only information about the physical aspects of the poster e.g. size, orientation.

( $\mathrm{PhD}$ candidate 5 - an international student from Asia)

The absence of formal feedback may well lead to uncertainties about the presentation of the poster rather than necessarily the research concepts and ideas that it expresses. This uncertainty is expressed in Vignette Six where, notably, the writer highlights the challenges associated with choosing appropriate colours and images to present an attractive representation of the research project rather than identifying challenges connected to the nature of the research project itself.

Vignette Six To me, a poster is a visual method to communicate your research. I think that the biggest benefit (and challenge) of presenting a poster in a conference, is that you need to convince people of keep reading, so accordingly, it needs to be persuasive and attractive. Once they have read it, people feel ready to ask you questions, and you can develop an actual conversation or discussion with them, so somehow is more casual and less stressing than other formats. A major challenge for me was to make the poster visual enough to choose the right colours and images. When you design a poster, these are equally important to the information you present.

(PhD candidate 6 - an international student from South America)

Yet, comparisons between Vignette Six and Vignette Seven illustrate a point made towards the beginning of the paper. That is, the content and features of the posters that are displayed are influenced by both the nature of the research projects and the characteristics of the candidates involved. At times, different levels of emphases will be placed upon these influences. Thus, while Vignette Six encourages us to reflect upon challenges relating to the aesthetics of the poster, Vignette Seven serves to remind us that another primary purpose of the poster is convey the central purposes of the research projects and to enable to audience to envisage how the various components of the these projects are synthesised to produce a coherent and integrated work.

Vignette Seven According to my experience, the two most challenging aspects are explaining the main purpose of the study and having clarity about the central components of the research. In addition, being opened (prepared) to any question or comments that may disagree with the study. All of these challenges are in the context of a very condensed (presentation) version of my research. To me, the main criteria I would use to asses a poster is consistency in how the different research sections are linked (i.e. introduction, literature review, methodology and 'findings and conclusions').

( $\mathrm{PhD}$ candidate 7 - an international student from South America)

\section{Conclusions}

The main purpose of the paper is to offer reflections about posters as visual representations of research studies conducted by $\mathrm{PhD}$ candidates. Our reflections have highlighted the multiplicity of purposes of posters and the diverse ways in which posters are assessed by audiences. In some cases, delegates may be viewing the posters primarily as works of art and be seeking creative forms of inspiration from them. In

International Journal of Management and Applied Research, 2020, Vol. 7, No. 3 
other cases, delegates may be searching primarily for insights into the latest thinking in a scientific domain and will assess the posters accordingly.

One of the main conclusions which we draw from these reflections is that attempts to judge posters from both aesthetic and academic perspectives involve highly subjective processes which often rely on unclear interpretations as to why the presenters have constructed the posters in the first place. Further, we draw attention to the fact that, on occasions, dissonances are likely to exist between what the creator of the poster is seeking from the visual representation of the research project and what members of the audience are seeking to acquire from this same representation. As such, the findings have application for various actors including those presenting posters, those viewing posters, and conference organisers. Thus, the findings indicate that there is merit in those presenting posters at $\mathrm{PhD}$ conferences being open about what they hope their posters will accomplish and, further, what role other conference delegates can play in achieving those goals. In the case of those viewing posters, there is merit in encouraging them to seek clarification from presenters about how they would like their posters to be judged in order for them to offer relevant and constructive feedback. Similarly, the findings of this study indicate that there is merit in conference organisers preparing delegates about how to approach the posters; this preparation should involve encouraging the delegates to allow the stated purposes of the posters to influence their judgements.

\section{References}

1. Anderson, M.S., Kot, F.C., Jie, Y., Kamata, T., Kuzhabekova, A. Lepkowski, C.C., Shaw, M.A., Sorenson, M.M. and Vasconcelos, S.M.R (2011), "Differences in national approaches to doctoral implications: implications for international research collaborations", In Anderson, M. and Steneck, N. (Eds), International research collaborations: much to be gained, many ways to get in trouble, New York: Routledge, pp. 169-190.

2. Berg, J. and Hicks, R. (2017), "Successful design and delivery of a professional poster", Journal of the American Association of Nurse Practitioners, Vol. 29, No. 8, pp. 461-469. https://doi.org/10.1002/2327-6924.12478

3. Brown, H. D. (2001), Teaching by Principles An Interactive Approach to Language Pedagogy, New-York: Longman.

4. Briggs, D.C. and Weeks, J.P. (2009), "The Impact of Vertical Scaling Decisions on Growth Interpretations", Educational Measurement: Issues and Practice, Vol. 28, No. 4, pp. 3-14. https://doi.org/10.1111/j.1745-3992.2009.00158.x

5. Brownlie, D. (2007), "Towards effective poster presentations: An annotated bibliography", European Journal of Marketing. Vol. 41, No. 11-12, pp. 1245-1283. https://doi.org/10.1108/03090560710821161

6. Carr, G., Loucks, D.P. and Blöschl, G. (2018), "Gaining insight into interdisciplinary research and education programmes: A framework for

International Journal of Management and Applied Research, 2020, Vol. 7, No. 3 
evaluation", Research Policy, Vol. 47, No. 1, pp. 35-48. https://doi.org/10.1016/j.respol.2017.09.010

7. Craddock, D and Mathias, H. (2009), "Assessment options in higher education", Assessment \& Evaluation in Higher Education, Vol. 34, No. 2, pp. 127-140. https://doi.org/10.1080/02602930801956026

8. Fakunle, O., Dollinger, M., Alla-Mensah, J. and Izard, B. (2019), "Academic conferences as learning sites: A multinational comparison of doctoral students' perspectives and institutional policy", International Journal of Doctoral Studies, Vol. 14, pp. 479-497. https://doi.org/10.28945/4383

9. Flaherty, E.A., Urbanek, R.E., Wood, D.M., Day, C.C., D'Acunto, L.E., Quinn, V.S. and Zollner, P.A. (2018), "A framework for mentoring students attending their first professional conference”, Natural Sciences Education, Vol. 47, No. 1, pp. 1-8. https://doi.org/10.4195/nse2017.10.0022

10. Kinikin, J and Hench, K. (2012), "Poster presentations as an assessment tool in a third/college-level Information Literacy course: an effective method of measuring student understanding of library research skills", Journal of Information Literacy, Vol. 6, No. 2, pp. 86-96. https://doi.org/10.11645/6.2.1698

11. Kuzhabekova, A. and Temerbayeva, A. (2018), "The role of conferences in doctoral student socialization", Studies in Graduate and Postdoctoral Education, Vol. 9, No. 2, pp. 181-196. https://doi.org/10.1108/SGPE-D-18-00012

12. Lynch, M.W. (2018), "Using conferences poster presentations as a tool for student learning and development", Innovations in Education and Teaching International, Vol. 55, No. 6, pp. 633-639. https://doi.org/10.1080/14703297.2017.1286999

13. Lynch, R., Mannix McNamara, P. and Seery, N. (2012), "Promoting deep learning in a teacher education programme through self and peer feedback", European Journal of Teacher Education, Vol. 35, No. 2, pp. 179-197. https://doi.org/10.1080/02619768.2011.643396

14. MacIntosh-Murray, A. (2007), "Poster presentations as a genre in knowledge communication: A case study of forms, norms, and values", Science Communication, Vol. 28, No. 3, pp. 347- 376. https://doi.org/10.1177\%2F1075547006298251

15. Mills, P.A., Sweeney, W.V., DeMeo, S., Marion, R and Clarkson, S. (2000), "Sessions as an alternative to written examinations: the poster exam", Journal of Education, Vol. 77, No. 9, pp, 1158-1161. https://doi.org/10.1021/ed077p1158

16. Moon, J. (2014), "Getting the measure of reflection: Considering matters of definition and depth", Journal of Radiotherapy in Practice, Vol. 6, No. 4, pp. 191 - 200. https://doi.org/10.1017/S1460396907006188

International Journal of Management and Applied Research, 2020, Vol. 7, No. 3 
17. Pedwell, R.K., Hardy, J.A. and Rowland, S.L. (2017), "Effective visual design and communication practices for research posters: Exemplars based on the theory and practice of multimedia learning and rhetoric", Biochemistry and Molecular Biology Education, Vol. 45, No. 2, pp. 249-261. https://doi.org/10.1002/bmb.21034

18. Persky, A.M. (2016), "Scientific posters: A plea from a conference attendee", American Journal of Pharmaceutical Education, Vol. 80, No. 10, p. 162. https://doi.org/10.5688/ajpe8010162

19. Quality Assurance Agency for Higher Education (QAA) (2011), The UK doctorate: a guide for current and prospective doctoral candidates, [Online] Available from: https://dera.ioe.ac.uk/10450/1/Doctorate_Guide.pdf [accessed on 24 July 2020].

20. Rees, C.J. and Rowlands, K.E. (2020), "Sign of mediocrity? Variability and uncertainty associated with $\mathrm{PhD}$ assessment processes in the UK", In: Antoniadou, M. and Crowder, M. (Eds.), Modern day challenges in academia: Time for change, Cheltenham: Edward Elgar Publishing, pp. 135-151. https://doi.org/10.4337/9781788119191.00017

21. Rogers, W. S. (1914), "The modern poster: Its essentials and significance”, Journal of the Royal Society of Arts, Vol. 62, No. 3192, pp. 186-195. https://www.jstor.org/stable/41341423

22. Tanner, P. and Chapman, J. (2012), "Poster presentations speak for themselves", The Language Teacher, Vol. 36, No. 3, pp. 15-19. https://doi.org/10.37546/JALTTLT36.3-3

International Journal of Management and Applied Research, 2020, Vol. 7, No. 3 